Accra Bespoke Multidisciplinary Innovations Conference (ABMIC)

\title{
Application of Artificial Intelligence (Al) Approach to African Real Estate Market Analysis Opportunities and Challenges
}

Odunfa, Victoria O.,

${ }^{1}$ Department of Estate Management

The Polytechnic, Ibadan

Ibadan, Oyo State, Nigeria

E-mail: odunfavictoria@gmail.com

Phone No: +234803483562

Fateye, Tosin B.

Department of Estate Managemen

Kaduna State University

Kaduna State, Nigeria

Phone No:

Adewusi, A.O.

Department of Estate Management

The Federal University of Technology

Akure, Ondo State, Nigeria

Phone No:

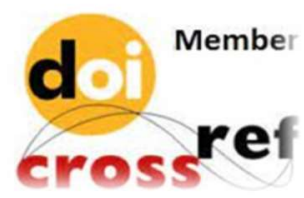

Proceedings Citation Format

Odunfa, V.O., Fateye, T.B. \& Adewusi, A.O. (2021): Application of Artificial Intelligence (Al) Approach to African Real Estate Market Analysis Opportunities and Challenges. Proceedings of the Accra Bespoke Multidisciplinary Innovations Conference. University of Ghana/Academic City University College, Accra, Ghana. December 2021. Pp 121-132 www.isteams.net/ghanabespoke2021. DOI https://doi.org/ 10.22624/AIMS/ABMIC2021P9 


\title{
Application of Artificial Intelligence (Al) Approach to African Real Estate Market Analysis Opportunities and Challenges
}

\author{
Odunfa, V.O., Fateye, T.B. \& Adewusi, A.O.
}

\begin{abstract}
The information on the real estate market is fast growing and becoming more complex to analyse. Therefore there is a need for reliable real estate market analysis for an informed and handsome investment decision making. The study examines the opportunities and challenges of using artificial intelligence (Al) approaches to analyse quantitative / data on the Africa real estate market. A systematic review of the literature was conducted. The study found some opportunities characterised by the usage of Al tools to include a reliable forecasting model, good predictive power, ability to perform complex tasks and analyses of a large number of variables. The major constraints of Al tools application in the study area include knowledge gap, weak political will, unstable economic conditions, low level of market transparency, maturity, openness and lack of availability and reliable data and research on the Africa real estate market analysis (AREMA). The study concluded that the Africa real estate market is yet to be ready for the adoption of hi-tech market analysis devices such as Al and machine learning (ML) due to lack of availability and reliable data. However, the study suggests a strong collaboration and cooperation between the public and private sectors to create enabling real estate business environment that prioritises technology infrastructure, data-driven property market and reliable databank to achieve a sustainable Africa real estate market analysis for an informed investment decision.
\end{abstract}

Keywords: Artificial Intelligence (Al), Africa, Real Estate, Market Analysis, Opportunities, Challenges, Analysis, Data, Environment.

\section{INTRODUCTION}

Information on real estate market has significant economic importance. The dynamic trend in the real estate market activities has a strong impact on economic growth and a nation's wealth creation. As recorded by the Bureau of Economic Analysis (BEA) in the first quarter (Q1) of 2021, the U.S. real estate sector comprises real estate, rental and leasing have the largest GDP, contributing more than $\$ 4$ trillion $(\$ 4,008,708,000,000)$ to the country's commonwealth. Also in the face of the Covid-19 pandemic, the sector grew by 3.4\% from Q1 2020- Q1 2021 and ranked No. 1 in their industry category 'finance, insurance and real estate' with an average industry output of \$7.87. In Africa, the Africa property investment (API) Summit 2021 noted that the real estate sector has remained at the forefront in driving the continent's economic recovery forward with more than $\$ 800$ million disclosed investment deal in the sector. Also, more efforts are still ongoing to attract more than 500 real estate investors across the globe. The summit identified among others, the high-profile real estate investment deals witnessed across the Africa property market. 
These include \$5.5 million refinance deal in Kenya, \$9 million investment deal in the Congo DR, \$10 million funding of Metroplex Mall in Uganda and \$300 million debt refinancing deal of Longo Real Estate, South Africa, which is currently the largest in the sub-Sahara Africa. The statistics suggest that the continent is fast becoming the real estate investment destination and a competitive market for vibrant property investment. However, to ensure the security and safety of the huge capital invested, grow expected on return, minimise risk, boost investor's confidence and pull investors across the globe, there is a need for a sustainable real estate market that is strongly driven by real-time data, technology innovations, ICT compliant and sophisticated market analytical model. However, one of the pragmatic approaches of achieving sustainable real estate market analyses is the application of artificial intelligence (Al) analytical tools which have been proved to be reliable, yielding a better and accurate results in the areas of market appraisal, trend analysis and forecasting (Taffese, 2006; Kabaivanov and Markovska, 2021).

Meanwhile, the use of Al has been far adopted and enjoyed in the developed real estate market especially in the U.S., U.K. and some fast-growing Asian economies such as China, Arab, Japan, and Malaysia etc. However, some parts of the world especially the less developed and developing continents including Africa are still far behind in the adoption and usage of the technology (Al). It is against this background that the study attempts to examine the application of artificial intelligence (Al) approaches to Africa real estate market analysis (AREMA) using a systematic literature review method. This was done to provide information on the opportunities provided with the use of Al tools and its attendant challenges to achieving a sustainable Africa real estate market.

\section{ARTIFICIAL INTELLIGENCE (AI) TOOLS IN REAL ESTATE}

Basic Concept of Artificial Intelligence

The term 'artificial intelligence is used to refer to a system that simulates human intelligence that is, it performs the task that is normally required of human intelligence. Chegut, Eichholtz and Kok (2017) and Everitt and Hutter (2018) explained that machines do not necessarily need to imitate the way humans behave to achieve a desirable result; however, the primary focus of $\mathrm{Al}$ is on acting rather than thinking, and doing rather than emulating humans; by the use of machine learning (ML) algorithm. According to Data Robot Al Experience (2018), machine learning (ML) is a form of artificial intelligence; a system leaning from the past to predict the future. Prado (2018) added that ML algorithms learn a historic relationship pattern between variables, establish a rule and apply it to the new set of data to predict the future outcomes in a high-dimensional space.

Meanwhile, Al \& ML algorithms differs from traditional statistical analytic models. The conventional analytical model performs on rule-based decision-making, Al \& ML perform tasks that are difficult to define through step-by-step-rule and it is applied to numerous business scenarios which its outcome depend on hundreds of factors that are difficult or impossible for a human to keep track of. Sadler (2018) posited that there are many cases in which both the normal statistics and machine learning models are used together to achieve higher accuracy and more clarity as to the causation of outcomes. Cearley et al. (2017) pointed out the importance of augmented analytics of $\mathrm{Al}$ as a form of artificial intelligence that is fast encroaching into human intelligence capacity in the business environment. Augmented analytical is the use of machine learning $(\mathrm{ML})$ to automate data processing, insight discovery and insight sharing of a broad range of business users, operational workers and citizen data scientists. 
The authors also noted that augmented analytics software helps to perform a complex analytical task, with little or no human supervision, therefore, increasing the analytic capabilities of business performance. But Al has some limitations in its operations. For instance, the system still requires hands-on machine learning methods to predict value; this implies that $\mathrm{Al}$ and $\mathrm{ML}$ are not independent.

\section{Al Tools in Real Estate}

In real estate, Conway (2018) highlighted some areas where the Al \& ML are applied to real estate services (See Table 1). Specifically, the author identified 'smart' building operation tools' powered by the Internet of Things (IoT) as one of the emerging real estate technologies that could be defined as artificial intelligence. These tools lean the building users' preferences for light, temperature and other space quality. Also, Simiak, Shavrov and Marina (2020) identified some of the property technology (proptech) that enhance growth in the real estate industry to include home machine tools, drones, virtual reality, building information modelling (BIM), data analytics tools, artificial intelligence, internet of thing (IOT), blockchain and smart contract.

Table 1: Real Estate Functions

\begin{tabular}{ll}
\hline Functions & Description \\
\hline Brokerage and Sales & Real estate product sales and leasing process \\
Property Management & Managing of building and tenant space \\
Property Data and Analytics & Real estate data collection, processing and data bank \\
Property development & Developing real estate for investors \\
Legal/contract & Real estate law/contract services \\
Location/Geospatial & Services related to mapping \\
Valuation & Evaluate current/future values of real estate \\
Real estate appraisal & Market studies/analyses \\
Facilities Management & Managing of facilities, workspace and occupants \\
Project Management & Managing real estate project/development \\
\hline
\end{tabular}

Source: Field Survey, 2021

In the same vein, Bishop (2006) classified ML in real estate as 'supervised' and 'unsupervised' learning. The formal entails the algorithm that observes the pattern of relationship between input variables/vectors to establish a rule(s) and applies them to new input variables to predict a future outcome refers to as target variable/vector. The supervised ML tasks comprise classification and regression problems.

While the latter i.e. the unsupervised learning differs in the sense that the outputs of the model are observations about the data itself otherwise known as unlabelled data. However, Chegut (2018) stressed that, despite the enormous opportunities characterised by machine learning of $\mathrm{Al}$, real estate is still very far away from contextual and usage of the machine learning algorithms. However, Fig. 1\&2 shows an illustration of an artificial neural network learning system and Table 2 illustrates the ML types, tools and areas of its application in real estate. 
EXHIBIT 11

Neural Networks

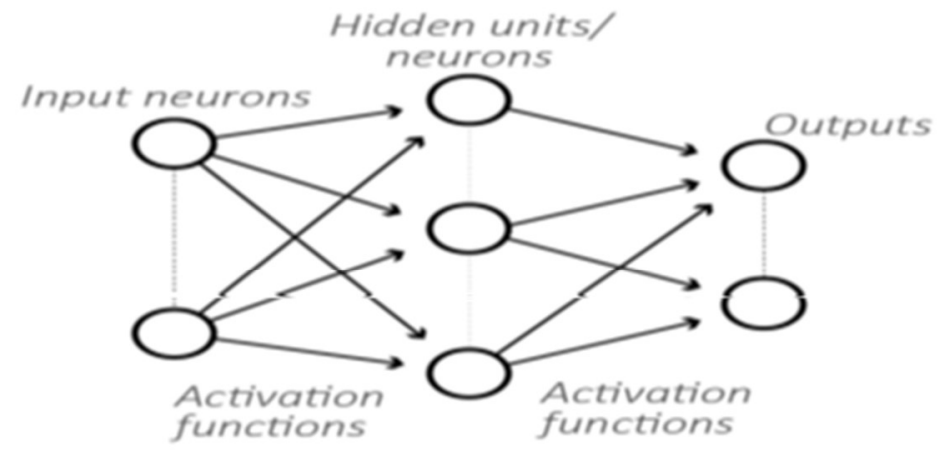

Neural networks consist of layers of hidden units created through activation functions that transform the data to achieve the end result outputs.

Fig. 1: Artificial Neural Networks Machine Learning of Al Source: Diagram extracted from Conway (2018)

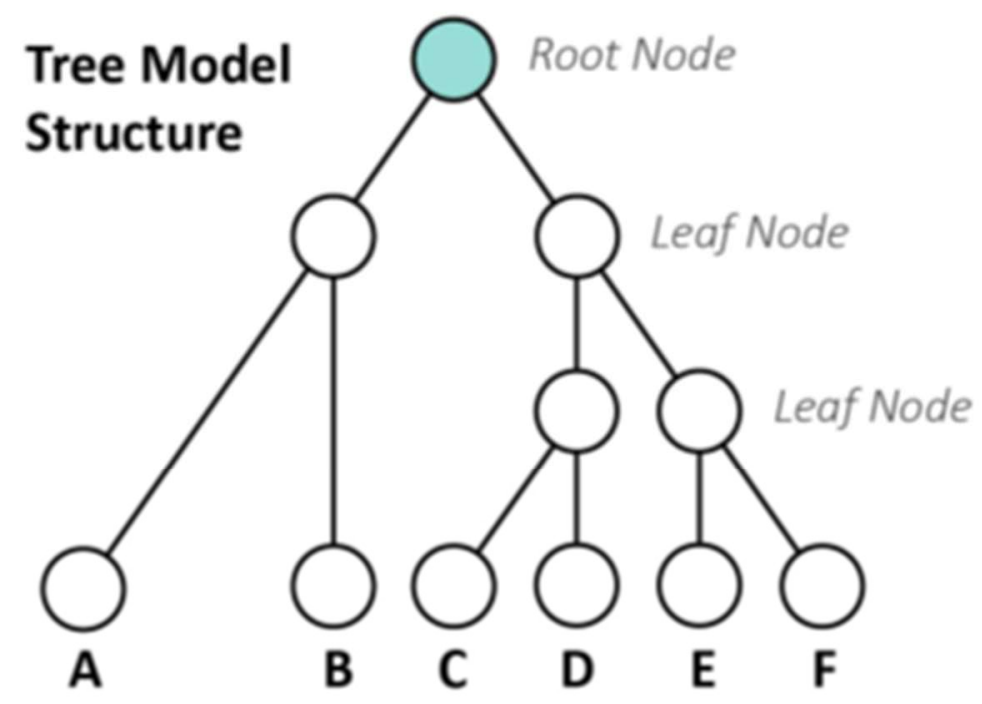

The full training dataset is the root node, which is then split into subsets depending on the variable with the highest predictive value. A-F are the resultina cateaorizations.

Fig. 2: Decision Tree Machine Learning of Al Source: Diagram extracted from Conway (2018) 
Data and information scientists have explained how some of the Al \& ML work. For instance, the artificial neural network (ANN) of Al which has become popular and far embracing in the business and financial world is largely use for data processing. The neural network is made up of systems of neurons similar to human organs and mimic human brain. A neural network system has a layer of interconnected nodes refers to as perceptron. The perceptron is similar to multiple leaner regressions; feeding on the signal produced on a multiple linear regression into an activation function that may be nonlinear. In a multi-layered perceptron (MLP), perceptron are arranged in interconnected layers.

The input layer collects input patterns. The output layer has classifications or output signals to which input patterns may map. The artificial neural network operates by capturing the variable input/vector, adapt to changing input; and give the best of result without needing to re-design the output criteria. However, the neural network machine learning algorithm is famous in the field of finance, time series processing, analysis and forecasting, constructing proprietary economic indicators, price derivatives, securities classification and credit risk modelling.

Meanwhile, authors have also raised concerns on the shortcomings of the machine learning algorithm of artificial intelligence across sectors. For instance, in the finance and accounting sector, Prado (2018) pointed out that financial machines do fail, and the quantitative machine learning mistakes do cause a great financial loss. In real estate, Conway (2018) emphasized the need to take caution when applying system algorithms to analyse scientific data including real estate to avoid the pitfalls characterised by the $M L \& A L$ tools.

The author raised issues such as bias-variance trade-off when optimising data for a high level of precision, the assumption of independent and identical distribution (IID) which may not be realistic in the real estate sector. Prado (2018) raised concern on the 'black box' which has to do with how neural network works and their interpretation in a business environment. Other grey areas include the generality of the algorithm purpose, the problem of hiring expertise and lack of data among others. 
Table 1: Al \& ML in Real Estate

\begin{tabular}{|c|c|c|c|c|}
\hline ML Types & Category & Task & Al Tools & Examples \\
\hline \multirow[t]{2}{*}{$\begin{array}{l}\text { Supervised } \\
\text { Learning } \\
\text { (Labelled Data } \\
\text { Set) }\end{array}$} & $\begin{array}{l}\text { Classification } \\
\text { (Predicting a } \\
\text { Category) }\end{array}$ & $\begin{array}{ll}\text { - } & \text { Image } \\
& \text { classification } \\
\text { - } & \text { Recommendation } \\
\text { - } & \text { Internet of Thing } \\
& \text { (loT) } \\
\text { - } & \text { Natural Language } \\
& \text { Processing }\end{array}$ & $\begin{array}{ll}\text { - Support } \\
\text { Vector } \\
\text { Clustering } \\
\text { (SVC) } \\
\text { - K-Nearest } \\
\text { Neighbours } \\
\text { (K-NN) } \\
\text { - Decision } \\
\text { Tree } \\
\text { - Neural } \\
\text { Network } \\
\text { - Naive Bayes }\end{array}$ & $\begin{array}{l}\text { To Split real } \\
\text { estate assets into } \\
\text { recommendations } \\
\text { for the highest } \\
\text { and best use } \\
\text { types based on } \\
\text { known attributes } \\
\text { using past }\end{array}$ \\
\hline & $\begin{array}{l}\text { Regression } \\
\text { (Predicting a } \\
\text { Value) }\end{array}$ & $\begin{array}{ll}\text { - } & \text { Valuation } \\
\text { - } & \text { Risk } \\
\text { - } & \text { Growth Analysis }\end{array}$ & $\begin{array}{l}\text { - Support } \\
\text { Vector } \\
\text { Machine } \\
\text { (SVM) } \\
\text { - Gradient } \\
\text { Boosted } \\
\text { Tree } \\
\text { - Neural } \\
\text { Network } \\
\text { - Decision } \\
\text { Tree } \\
\text { - Random } \\
\text { Forest } \\
\text { - Linear } \\
\text { Regression }\end{array}$ & $\begin{array}{l}\text { To predict real } \\
\text { estate asset } \\
\text { values given a set } \\
\text { of asset qualities } \\
\text { and market } \\
\text { characteristics }\end{array}$ \\
\hline \multirow[t]{2}{*}{$\begin{array}{l}\text { Unsupervised } \\
\text { Learning } \\
\text { (Unlabelled } \\
\text { Data Set) }\end{array}$} & $\begin{array}{l}\text { Clustering } \\
\text { (Predicting a } \\
\text { Category) }\end{array}$ & $\begin{array}{ll} & \text { Data Mining } \\
- & \text { Geo-location } \\
& \text { Patterns } \\
\text { - } & \text { Object } \\
& \text { Tracking/Image } \\
& \text { Processing }\end{array}$ & $\begin{array}{ll}\text { - } & \text { K Means } \\
\text { - Mean Shift } \\
\text { - Gaussian } \\
\text { Mixture } \\
\text { Models }\end{array}$ & $\begin{array}{lr}\text { To divide } & \text { assets } \\
\text { into groups based } \\
\text { on physical } \\
\text { proximity } \quad \text { and } \\
\text { building rr } \\
\text { attributes. }\end{array}$ \\
\hline & $\begin{array}{l}\text { Diversionary } \\
\text { Reduction } \\
\text { (Just } \\
\text { Looking) }\end{array}$ & $\begin{array}{ll} & \text { Data } \\
& \text { visualisation } \\
\text { - } & \text { Data } \\
& \text { Compression } \\
\text { - } & \text { Internet of thing } \\
& \text { (loT) }\end{array}$ & $\begin{array}{l}\text { - } \text { Principal } \\
\text { Components } \\
\text { Analysis } \\
\text { (PCA) } \\
\text { - Linear } \\
\text { Discriminant } \\
\text { Analysis } \\
\text { (LDA) } \\
\text { - Spectral } \\
\text { Embedding }\end{array}$ & $\begin{array}{l}\text { To simplify } \\
\text { transform real } \\
\text { estate data } \\
\text { produced by loT } \\
\text { enable devices } \\
\text { such as } \\
\text { sales/rental as } \\
\text { prices, location } \\
\text { attributes/factors }\end{array}$ \\
\hline Reinforcement & $\begin{array}{l}\text { Unknown } \\
\text { Outcomes }\end{array}$ & $\begin{array}{ll}- & \text { Construction } \\
& \text { (Root Navigation) } \\
\text { - } & \text { Learning } \\
\text { - } & \text { Decision Making } \\
\text { - } & \text { IOT }\end{array}$ & $\begin{array}{l}\text { - Value } \\
\text { function } \\
\text { - } \text { Monte Carlo } \\
\text { - Neural } \\
\text { Networks }\end{array}$ & \begin{tabular}{lr} 
To test & and \\
remember many \\
potential \\
outcomes \\
millions of \\
different move \\
\multicolumn{2}{l}{ combinations }
\end{tabular} \\
\hline
\end{tabular}




\section{APPLICATIONS OF ARTIFICIAL INTELLIGENCE (AI) TO REAL ESTATE MARKET ANALYSES A SYSTEMATIC REVIEW OF LITERATURE}

The real estate market is characterised by multi-task activities which are complicated in many cases. Every real estate market is unique and largely driven by local-specific factors such as economic, social and political. This suggests that the analysis of the real estate market is largely independent, fraught with difficult decisions, challenging relationships and a multitude of variables. Therefore, there is a need to develop tech-driven analytical tools that will facilitate the optimisation of a large volume of real estate data for effective use.

As observed by Kabaivanov and Markovska (2021), the abundance of information on real estate markets and transactions requires sophisticated machine learning (ML) analytical tools such as artificial intelligence for data optimization and improvement. Conway (2018) expressed that today's real estate market challenges are becoming more complex, the use of artificial intelligence (Al) approach to solving the emerging challenges will help the sector to be more proactive, efficient and data-driven in all aspects including property/project/facility management, valuation/appraisal, investment decision and physical development process.

Meanwhile, a large body of literature has examined the applications of the artificial intelligence approach to real estate market activities. Yu and Yan (2020) used the neural network algorithm of artificial intelligence to check the forecast potential problems in time series analysis. The function of the Al among others is to identify outliers and examine the feature of the analysed time-series data such as stationary, autocorrelation and predictive ability. The authors concluded that neural network algorithms can be explored with similar data in the real estate market. Also, as a result of some unique features of the real estate market especially the ones associated with a longer period of closing transaction deals and the influence of economic shock, Wang, Lu and Ma (2020) recommended the integration of Al software to real estate market analyses. The authors explained that the use of the neural networks Al tool will help in portfolio rebalancing and detect early problems for informed investment decision making.

Costantino, Di Gravio and Nonino (2015) and Hung (2018) noted the importance of artificial intelligence methods in project management. The authors posited that real estate projects especially for investment purposes are faced with several risks such as site selection, financial, time, technical, economic, market, institutional/government intervention etc. However, the use of neural network Al will help in critical analysis of project scenarios at different points in time in general and a case-specific analysis. The study recommends the adoption of Al for better financing options and to increase the chances of project critical success factors.

Similarly, Case, Clapp, Dubin and Rodriguez (2004), Wang, Chang and Wang (2019) and Calka (2019) use the spatial autocorrelation method (Geo-statistics) to analyse the change in real estate prices and concluded that the use of Al tools will not only give accurate valuation but will improve timing required to implement complex investment plans. Also, Manganelli and Morano (2014) concluded that the real estate sector needs accurate appraisals of property value because the several objectives of stakeholders are under the control of real estate values or returns. 
Giudice, Paola and Forte (2017) researched to interpret the existing relationship between real estate rental prices of housing units and their respective geographical locations in the Chiaia neighbourhood of Italy using a genetic algorithm (GA). The authors justified the use of the Al approach (GA) to appraise the real estate housing market, expressed that GA ensures reliability and possesses high predictive and accuracy potential. The study however submitted that the rapid rate at which real estate market analyses is growing, the emerging difficulties in the forecasting and the relevant knowledge required for real estate prediction, investment and tax issues have necessitated the need to explore alternative approaches such as artificial neural networks that could provide reliable predictions and information on real estate value and market analysis. Similarly, Pinter, Amir and Felde (2020) and Rhoads et al. (2020) work emphasised the need to deploy an advanced accurate predictive model to explain real estate price behaviour modelled. The authors opined that reliable real information of estate market analysis is essential to urban development and critical to economic functions. The study however recommends the use of Al approaches such as call detail records (CDR), claiming that CDR is a novel machine learning method that tackles real estate modelling complexities.

In addition to these, authors have attested to the outstanding performance of artificial intelligence approaches to real estate market analysis. for instance, Ishaku and Lewu (2021) used an artificial neural network to predict the auction values of real estate in Ghana. Simiak, Shavrov and Marina (2020) investigated to know whether propech tools such as home machine tools, drones, virtual reality, building information modelling (BIM), data analytics tools, artificial intelligence, internet of thing (IOT), blockchain and smart contract among others and posited that proptech devices do not only have a positive impact on the real estate industry growth, but the advent property technology innovations have continued to change the structure of real estate market, increase in demand for hi-tech tools in property management, encouraging new skills and enhance flexible policy challenges for estate industry. Similarly, Kang et al. (2020) developed a forecasting model for real estate auction prices using a genetic algorithm (GA). The authors concluded that the GA model exhibits optimum performance, effective tool for regional segregation and improve predictive accuracy.

\section{AFRICA REAL ESTATE MARKET CONSTRAINTS TO ADOPTION OF AI \& ML TOOLS}

Despite the vibrant potential of the Africa property market for real estate investment, the property market is plagued with many challenges. RICS (2014) and Knight Frank (2017) research on Africa real estate market reported that except for the South Africa property market, other property markets on the continent have not experienced a major improvement. The reports identified some of the critical problems faced in most of the Africa property market to include weak infrastructure, poor business and institutional environment, high level of corruption and professional skills gap. Other challenges pointed out include weak political will, unstable economic condition, low level of market transparency, maturity, openness and lack of availability and reliable data and research on the African real estate market.

Meanwhile, the highlighted challenges and others have created a clog in the wheel of adopting Al to the Africa real estate market analysis. For instance, the inability of the government to facilitate and promotes an economic and business environment that prioritises infrastructure such as prop-tech, encourage the development of a strong institutional framework and the bridge knowledge gap. Also, the private sector of the economy that is supposed to lead the sustainable development in different sectors of the African countries and by extension the real estate market in ICT and technology innovation has been bereaved with ill-political interference. 
The unhealthy government policies on physical development control and regulation, bad governance and undeveloped property taxation system have been the major constraints sustainable protection market structure, creating a frightening and uncertain business environment.

Another major constraint hampering the application of a hi-tech artificial intelligence tool is the lack of availability and reliable real estate dataset. The lack of real-time real estate property data pointed out to be the critical reason while a larger number of Africa countries including Nigeria, Egypt, Morocco, Zambia, Rwanda and Ghana were ranked to be low transparent including in technology and databank (JL-Lasalle, 2020). The report expressed that the majority of African real estate markets regulation is still nascent and not yet matured. By implication, trending information on Africa real estate market are yet to be readily available, open and free flow, while the available ones may lack credibility. While the application of machine learning and artificial intelligence devices requires a big and larger volume of the dataset to function optimally, the availability and adequacy of reliable data that guaranteed sustainable real estate market analysis for potential investors remain a great concern.

\section{CONCLUSION AND PRACTICAL IMPLICATIONS}

The study examines the application of artificial intelligence (Al) to real estate market analysis with a focus on the Africa property market. The primary objectives of the study are to reveal the opportunities characterised by the application of the Al approaches and their major constraints. A systematic literature review method was employed. The study found that countries that have embraced the use of Al enjoy benefits such as a reliable forecasting model, good predictive power, ability to perform complex tasks and analyses of a large number of variables. While in the Africa real estate markets, except South Africa, others were categorised as nascent, low transparent and non-matured. The major constraints include knowledge gap, weak political will, unstable economic condition, low level of market transparency, maturity, openness and lack of availability and reliable data and research on the African real estate market.

The study, therefore, concluded that while god number of the Africa real estate markets are yet to be ready for adoption of hi-tech market analysis devices such as Al and ML due to lack of availability and reliable data, there is a need for continuous appraisal of the Africa property market to measure her level of improvement especially in technology advance, maturity and transparency, while collaboration and corporation of both the public and private sectors should be encouraged resulting into the creation of enabling real estate business environment that prioritises technology infrastructure and data-driven property market and reliable databank to achieving a sustainable Africa real estate market. 


\section{REFERENCES}

1. Africa Property Investment Summit (API) (2021). Africa Property: A New Era. 12th Annal API Summit

2. Bishop, C. M. (2006). Pattern Recognition and Machine Learning. (B. Jordan, Michael; Kleinberg, Jon; Scholkopf, Ed.), Information Science and Statistics. Springer. https://doi.org/10.1117/1.2819119

3. Bureau of Economic Analysis (BEA) (2021) U.S. Department of Commmerce, Suitland, United State

4. Calka, B. (2019). Estimating residential property values on the basis of clustering and Geostatistics. Geosciences 19(3):143

5. Case, B., Clapp, Dubin R. J. and Rodriguez, M. (2004). Modeling spatial and temporal house price patterns: A comparison of four models. The Journal of Real Estate Finance and Economics, 29(2): 167-191

6. Cearley, D. W., Burke, B., Searle, S., and Walker, M. J. (2017). Top 10 Strategic Technology Trends for 2018. Gartner. https://www.gartner.com/doc/reprints

7. Chegut, A., Eichholtz, P., and Kok, N. (2017). The Price of Innovation: An Analysis of the Marginal Cost of Green Buildings (working paper). MIT: Center for Real Estate.

8. Costantino, F., Di Gravio, G. and Nonino, F. (2015). Project selection in project portfolio management: An artificial neural network model based on critical success factors. International Journal of Project Management, 33(8) 1744-1754

9. Conway, J. (2018). Artificial Intelligence and Machine Learning: Current Applications in Real Estate. M.Sc. Thesis, Program in Real Estate Development in Conjunction with the Center for Real Estate, Massachusetts Institute of Technology, United States.

10. Data Robot Al Experience. (2018). Boston.

11. Everitt, T., and Hutter, M. (2018). Universal Artificial Intelligence. In H. A. Abbass \& D. J. Reid (Eds.), Foundations of Trusted Autonomy. Springer.

12. Giudice, D. V., Paola, D. P. and Forte, F. (2017). Using genetic algorithms for real estate appraisals. Buildings, www.mdpi.com/journal/buildings

13. Hung, L. (2018). A risk assessment framework for construction project using artificial neural Network. Journal of Science and Technology in Civil Engineering (STCE)-NUCE, 12(5): 51-62

14. Ishaku, M. M. and Lewu, I. H. (2021). Research on the effect of artificial intelligence real estate forecasting using multiple regression analysis and artificial neural network: A case study of Ghana. Journal of Computer and Communications, 9: 1-14

15. Jones Lang Lasalle (2020). Global transparency index: key findings in 2020. http://www.jll.com/

16. Kabaivanov, S. and Markovska, V. (2021). Artificial Intelligence in Real Estate Market Analysis. AIP Conference Proceedings, https://doi.org/10.1063/5.0041806

17. Kang, J., Lee, J. H., Jeong, H. S., Lee, S. H. and Oh, J. K. (2020). Developing a forecasting model for real estate auction prices using artificial intelligence. Sustainability, 12, 1-19 doi:10.3390/su12072899

18. Knight Frank (2017). Real Estate markets in a continent of growth and opportunity. Africa Annual Report 2017/18. KnightFrank.com/Research

19. Manganelli, B. and Morano, P. (2014). Estimating the market value of the building sites for homogeneous areas. Adv. Mater. Res. 14-19.

20. Pinter, G., Mosavi, A. and Felde, I. (2020). Artificial intelligence for modeling real estate price using call detail records and hybrid machine learning approach. Entropy www.mdpi.com/journal/entropy 
21. Prado, M. L. De. (2018). The 10 reasons most machine learning funds fail. www.QuantResearch.org

22. Rhoads, D., Serrano, I. Borge-Holthoefer, J. and Solé-Ribalta, A. (2020). Measuring and mitigating behavioural segregation using call detail records. EPJ Data Science, 9: 1-17. https://doi.org/10.1140/epjds/s13688-020-00222-1

23. Sadler, M. P. (2018). Data Science and Advanced Analytics : An integrated framework for creating value from data. https://www.salesforce.com/products/einstein/overview/

24. Siniak, N., Kauko, T., Shavrov, S. and Marina N. (2020). The impact of proptech on real estate industry growth. IOP Conf. Series: Materials Science and Engineering 869 (2020) 062041. doi:10.1088/1757-899X/869/6/062041

25. Taffese, Z. W. (2006) A Survey on Application of Artificial Intelligence in Real Estate Industry. Proceedings of the Third International Conference on Artificial Intelligence in Engineering \& Technology November 22-24, Kota Kinabalu, Sabah, Malaysia

26. Viruly, F. and Hopkins, N. (2014). Unleashing Sub-Saharan Africa Property Markets. rics.org/research

27. Wang, C. W., Chang, J. Y. and Wang, Y. J. (2019). An application of the spatial autocorrelation method on the change of real estate prices in Taitung City. ISPRS International Journal of Geo-Information, 8(6): 249

28. Wang, P., Lu, Z. and Ma, Y. (2020). An integrated early warning system for stock market turbulence. Expert Systems with Applications, 153(1) 1-14

29. Yu, P. and Yan, X. (2020). Stock price prediction based on deep neural networks. Neural Computing and Applications, 32(6): 1609-1628 